\title{
COMMENTARY
}

\section{Cinderella science}

\section{On-the-ground monitoring is unglamorous work, seldom rewarded by funding agencies or the science community. But we neglect it at our peril, warns Euan Nisbet.}

S ometimes discovery comes slowly, not with a flash of revelation but creepingly, as larger patterns emerge painfully from years of data. Researchers who work in Mauna Loa, Hawaii, are celebrating the fiftieth anniversary of a measurement programme responsible for the longest continuous recording of atmospheric carbon dioxide. Seldom can such insight have grown (and continued to grow) over so long a time. Now that we look back, the resulting 'Keeling curve' of $\mathrm{CO}_{2}$ concentrations ranks very high indeed among the achievements of twentieth-century science.

Charles David Keeling's account of his tribulations ${ }^{1}$, "Rewards and penalties of monitoring the Earth", should be compulsory reading for politicians and science administrators. Idealistic young scientists, as yet unscarred, should read it and take note: courage and perseverance are required. Before Keeling, little was known about $\mathrm{CO}_{2}$ in the atmosphere and available measurements had little value. Success came from Keeling's painstaking years of effort and innovation. Despite the import of the results, the work was often threatened, as is attested by a gap in 1964 when underfunding briefly halted measurement.

Monitoring is science's Cinderella, unloved and poorly paid. Sustaining a long-term, ground-based programme that demands high analytical standards remains challenging. Funding agencies are seduced either by 'pure' notions of basic science as hypothesis-testing, or by the satanic mills of commercial reward. Neither motive fosters 'dull' monitoring because meeting severe analytical demands is not seen as a worthwhile investment. At one stage, Keeling was ordered to guarantee two discoveries per year and today, modern research has become a planned journey through set 'milestones' to deliverable destinations.

"The Mauna Loa curve thrust itself before humanity's eyes, changing our view of the world."

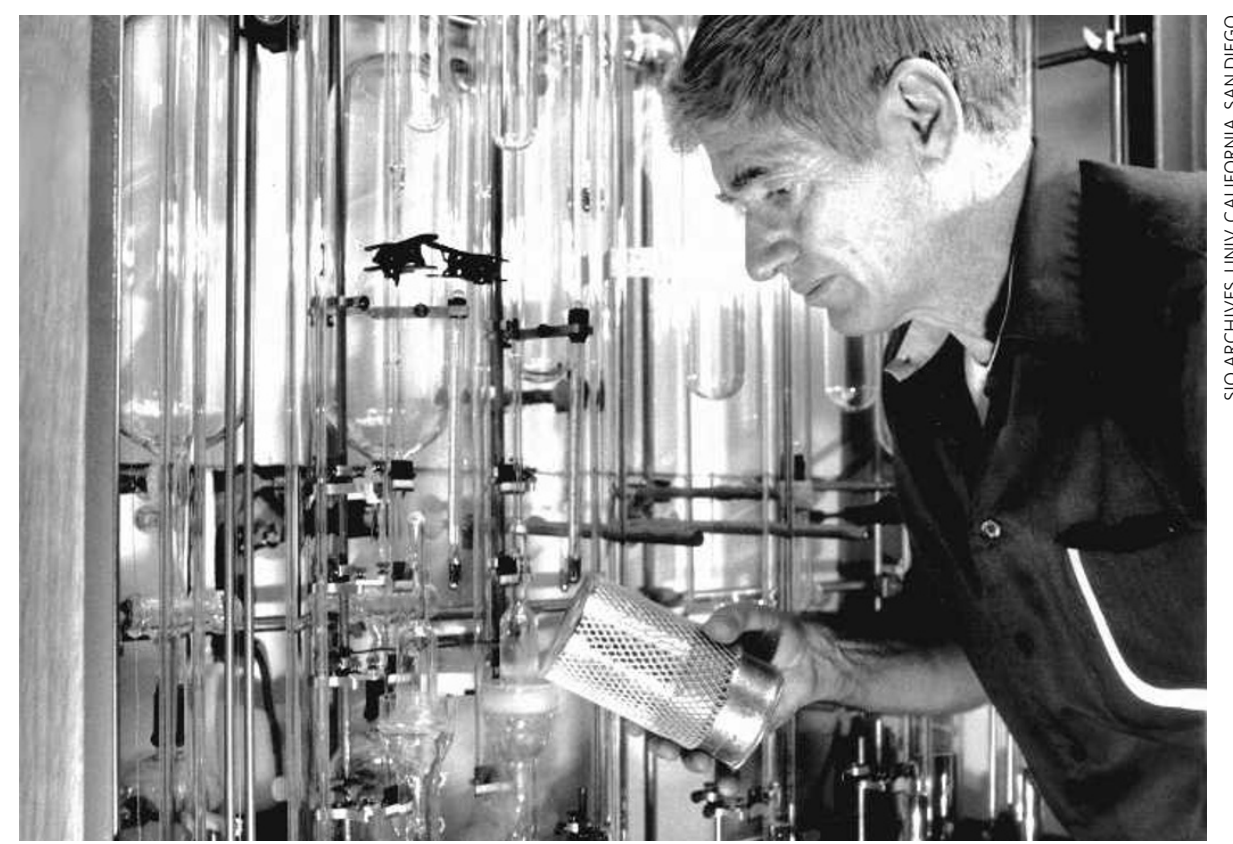

Charles David Keeling's work made us aware of rising amounts of carbon dioxide in the atmosphere.

release in the Northern Hemisphere. Keeling measured the isotopic abundance of carbon-13 in $\mathrm{CO}_{2}$ to show that the seasonal changes were caused by land plants.

Keeling's first report is a landmark ${ }^{2}$, documenting the seasonal cycle and, more gloomily, the annual rise in $\mathrm{CO}_{2}$. By the 1970s, the biological influence of the El Niño/Southern Oscillation became clear as climate shifts altered the seasonal $\mathrm{CO}_{2}$ cycle. And the connection between rising $\mathrm{CO}_{2}$ and fossil-fuel burning was firmly established, showing that a substantial fraction of $\mathrm{CO}_{2}$ added by humans remains in the atmosphere and is not removed by the biosphere.

The Mauna Loa curve, simple and unambiguous, thrust itself before humanity's eyes, changing our view of the world. Keeling's work was far ahead of its time. It was the 1970s before other quality-controlled data sets got going. Had we not had his long backrecord, awareness of global change would have come more slowly. Sudden events, such as the marked fluctuations in global $\mathrm{CO}_{2}$ uptake after the 1991 volcanic eruption of Mount Pinatubo, may have looked very different in the context of a 15-year rather than a 30-year record.
Global understanding is underpinned by rigorous in situ (measured on the surface) long-term data series. Since 1957, satellites have patrolled the skies, and they are crucial for the wider picture. But they need to work in partnership with the much more accurate in situ monitoring. Satellite monitoring originally missed the ozone hole, found by careful ground measurements. Following Keeling's example, in situ measurement spread across the globe. The World Meteorological Organization (WMO) set up the Global Atmosphere Watch, widening the coverage of the US National Oceanic and Atmospheric Administration (NOAA) network, to monitor long-lived $\mathrm{CO}_{2}$, methane, nitrous oxide and other greenhouse gases on a global scale.

\section{In it together}

Nearly all the G8 powers, plus China, Brazil and Indonesia, share in the WMO network. Dozens of countries help, from Kenya to Kyrgyzia. Far-flung huts hum with recording instruments - from the Cape of Good Hope, to Alert in Arctic Canada, Zeppelin in Spitsbergen, Norway, and Cape Grim in Tasmania. Supporting the continuous measurements, groups regularly collect air flasks at many locations worldwide. Guiding the work is the traced the breathing of the biosphere, dominated by springtime $\mathrm{CO}_{2}$ uptake and autumn 


\section{THE WORLD'S $\mathrm{CO}_{2}$ MEASURING STATIONS}

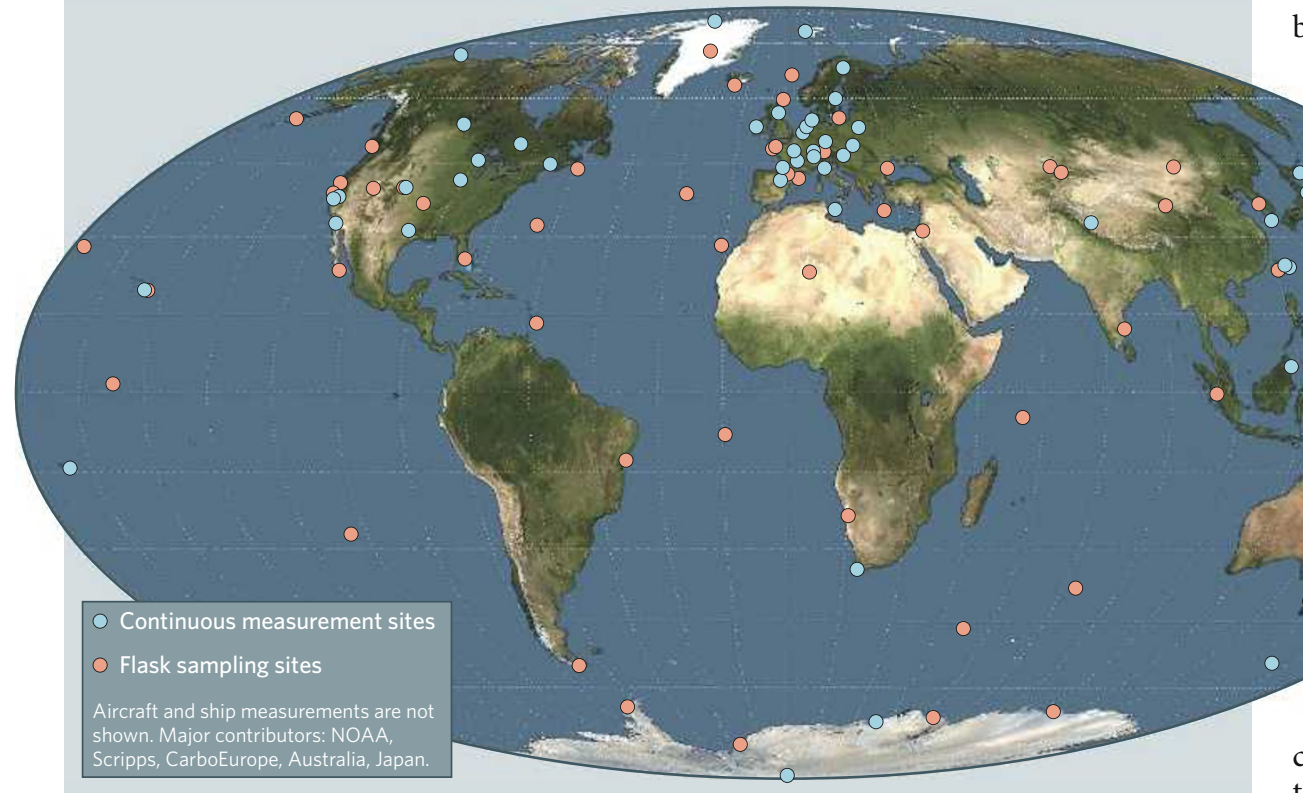

expert panel on $\mathrm{CO}_{2}$ and trace gases, the inheritor of Keeling's enthusiasm. This is the United Nations at its very best, acting for humanity.

"Trust, but verify," said Ronald Reagan of the 1987 US-Soviet nuclear-missile treaty. International agreements such as the Kyoto Protocol can succeed only when verified. Unless independently audited, self-declared emissions reported by individual nations cannot be trusted. Without trust, any Kyoto follow-up treaty surely cannot succeed. Here, measurement promises much. Projects such as NOAA's CarbonTracker, and CarboEurope run by the European Union (EU), offer hope of real validation. Long records of concentration and isotopic data, when modelled with meteorological information, should eventually enable full understanding of global and regional carbon-gas budgets, by location, season and by source or sink type.

\section{The devil is in the detail}

As we face an uncertain planetary destiny, modellers seek to interpret the past and predict the future. But comprehension requires good in situ data - quality is crucial if we are to understand the long-term increase in greenhouse gases in the air by computer modelling. To achieve deep insights from both data and models, curiosity-driven scientists need to work closely with analysts and technicians who can build innovative instrumentation. Without trustworthy measurement, we cannot understand the system of Earth.

And the gaps remain huge, especially on land in the tropics, the heart of the biosphere (see map). Southern Asia, immensely important to both land biosphere and world economy, is barely measured. Africa and South America have few tropical stations. Isotopic records of carbon gases, potent in identifying sources, are nowhere continuous. Measuring oxygen concentrations provides insight into biosphere uptake of $\mathrm{CO}_{2}$, but the monitoring network is small. Nitrous oxide, an easy target for greenhouse reduction but needing precise measurement, is monitored in too few places. Global cooperation is hindered by EU rules on the safety testing of gas cylinders.

The problems faced by Keeling have not gone away. Above all, data sets need to be long-term, sustained over the decades. It is easier to get big funding for one-off projects than small funding for long-term infrastructure. Although in situ monitoring is cheap, stations frequently face closure and vital time series are broken. Sustaining continuity and quality is hard. A few years ago, Australia's outstanding programme - now recovering - was savaged by budget cuts. Although German help maintained former Australian monitoring in Scot-

land, the important carbon-13 time series at Cape Rama on the Indian coast, tracking the monsoon winds, ended. Australia's withdrawal leaves a large gap in southern Asia, at a time when regional efforts need to increase.

In Europe, although Brussels supports projects such as CarboEurope and Geomon, there is no long-term funding commitment. For example, the EU's methane-monitoring network was terminated, with responsibility left to individual nations, although the winds heed no national borders. Satellite infrared monitoring helps, but, needing sunlight, it is blind to methane emissions at night. A better EU policy would support close partnership, not competition, between in situ and space observations.

Uniquely among the major nations, Britain does not support atmospheric $\mathrm{CO}_{2}$ monitoring. To fill the gap, the EU funds measurements in Britain and marine $\mathrm{CO}_{2}$ work, the United States collects from remote UK islands and France monitors the North Atlantic background levels.
However, the UK absence has consequences for understanding the changing oceanic carbon sink in the South Atlantic - where most

of the islands are UK territories - and limits the development of new measurements in the tropics, even though this is a perfect role for the Commonwealth.

Many of Keeling's problems came from the views of the scientific community itself. In situ work promises neither shiny rockets nor lucrative contracts. Monitoring does not win glittering prizes. Publication is difficult, infrequent and unread. Keeling's extraordinary 1960 paper garnered citations slowly. When funds are available for climate research, money chases exciting modelling, whereas funds for the underlying monitoring data have to be boot-legged. Modellers are very supportive, recognizing their dependence on gathering true data, but funding committees are not. Despite Keeling's successes, long-term measurement is simply not valued as 'discovery' science.

There is hope. Driven by Keeling's example, the world's unlikely hero - considering its global-warming stance - is the United States. The Scripps Institution of Oceanography in La Jolla, California, where Keeling's son Ralph now works, Princeton University in New Jersey and NOAA deserve praise. Many other nations sustain similar high-quality measurement and Brazil and other concerned tropical countries are starting to make contributions. But moves in Brussels to create an integrated European carbon observing system as a matching partner for NOAA need support. Southern Asia, now becoming wealthy, should do much more, as should the Middle Eastern nations.

Despite the importance of his discovery, Keeling, who died in 2005, was not awarded a Nobel prize. A better monument to his work would be an improved UN Global Atmosphere Watch for greenhouse gases. It is time to build on that, to gain stronger, more permanent commitment by many nations, and to sustain and expand the global in situ measurement network, especially in the tropics. The reward will be global security through climate knowledge. With precise, quality-controlled data, we shall better comprehend the Earth system and the breathing of the planet, watch the greenhouse, verify Kyoto, and gain warning of dangers to come.

Euan Nisbet is in the Atmospheric Group,

Department of Geology, Royal Holloway, University of London, Egham, Surrey TW20 OEX, UK.

1. Keeling, C. D. Annu. Rev. Energy Environ. 23, 25-82 (1998).

2. Keeling, C. D. Tellus 12, 200-203 (1960). 